\title{
SISTEM INFORMASI LAPORAN JASA PENGIRIMAN BARANG PADA CV. MITRAJASA PERDANA ANUGRAH BERBASIS WEB
}

\author{
Diwahana Mutiara Candrasari Hermanto ${ }^{1}$, Anggi Anggraini ${ }^{2}$ \\ Program Studi Teknik Informatika, STIKOM Yos Sudarso ${ }^{1}$ \\ Program Studi Sistem Informasi, STIKOM Yos Sudarso ${ }^{2}$ \\ *Email candrasari5860@stikomyos.ac.id ${ }^{1}$, angelmerici2@gmail.com ${ }^{2}$
}

\begin{abstract}
ABSTRAK
CV. Mitrajasa Perdana Anugrah merupakan perusahaan yang bergerak dalam bidang jasa pengiriman barang dari perseroan komanditer yang menyediakan jasa pengiriman. Dalam menjalankan usahanya CV. Mitrajasa Perdana Anugrah belum menggunakan komputer untuk mencatat transaksi tetapi masih menggunakan buku secara manual,sehingga membuat data menjadi tidak efisien, karena seringkali terjadi kesalahan dalam menulis, buku yang digunakan bisa saja terkena air dan membuat data menjadi tidak bisa dibaca, dan kerap kali buku catatan lupa meletakkannya bahkan buku tersebut hilang dan menyebabkan kerugian bagi CV. Mitrajasa Perdana Anugrah, dengan membangun Sistem Informasi Laporan Jasa Pengiriman Barang Berbasis Web Pada CV. Mitrajasa Perdana Anugrah diharapkan dapat mengatasi masalah yang dihadapi oleh CV. Mitrajasa Perdana Anugrah tersebut. Aplikasi Sistem Informasi Laporan Jasa Pengiriman ini dibangun dengan menggunakan bahasa pemrograman $P H P$ dan sistem manajemen basisdata yang digunakan adalah $M y S Q L$. Aplikasi ini dapat memberikan informasi mengenai data pengirim, data penerima, data pengiriman, data kurir, laporan pengirim, laporan penerima, laporan pengiriman, laporan kurir, sehingga memudahkan untuk diakses oleh pengguna. Pemilik juga dapat melihat laporan secara cepat karena aplikasi sistem informasi laporan jasa pengiriman barang ini dibangun berbasis web yang dapat diakses dengan mudah, cepat, serta akurat diamna saja dan kapan saja, sehingga dapat mempercepat pengambilan keputusan.

Kata kunci: Sistem Informasi Laporan Jasa pengiriman Barang, Prototype,Web, Paired Samples T-Test, Usecase Diagram
\end{abstract}

\begin{abstract}
CV. Mitrajasa Perdana Anugrah Is the company which are engaged in cargo transport services of the company komanditer located on jl .Raya kober gg.Manggis no 3 ( front of market kober sub-district regency banyumas provincial central java. In running their business $c v$.Mitrajasa prime gift not using a computer to records the transactions but still use books manually, so as to make data to inefficient, as often happens mistake in writing, the book used could have been exposed to water and make data be unable to read, and often books forget put it even the book missing and causing loss for CV. Mitrajasa Perdana Anugrah, by building information system report cargo transport services web-based in CV. Mitrajasa Perdana Anugrah. Is expected to overcome the problems faced by CV. Mitrajasa Perdana Anugrah. The Application information system delivery service report is built with a use of language programming php and database management system used is mysql. This application can inform the sender, regarding the data recipients, data delivery, data courier, the sender, report the reports on the recipients, delivery, report courier, report so easier to accessed by the user. Could also see in the report quick application report information system was built cargo transport services web-based that can be accessed easily, fast, and accurate anytime, so to speed up decision-making.

Keywords : Information system report cargo transport services, Prototype, Web, Paired Samples T-Test, Usecase Diagram
\end{abstract}




\section{PENDAHULUAN}

Dalam perkembangan jaman yang semakin canggih seperti saat ini, teknologi merupakan solusi untuk mengatasi segala keterbatasan akses, seperti jarak dan waktu. Untuk itu dalam perkembangannya diciptakan teknologi yang dapat mengatasi permasalahan tersebut. Salah satu solusi yang ditawarkan adalah dengan diciptakannya $w e b$. Dengan menggunakan web maka seseorang dapat mengakses sebuah informasi dengan lebih cepat tanpa terkendala oleh jarak dan waktu. Seiring berjalannya waktu perkembangan teknologi informasi berdampak pada perkembangan sebuah perusahaan atau sebuah organisasi.

Dalam menjalankan usahanya sebuah perusahaan penyaluran yang mapan sama dengan produsen yang sudah memiliki visi dan misi. Bahkan perusahaan penyalur yang mumpuni sudah memiliki sistem yang sangat baik sejajar dengan yang dimiliki produsen. (Royan, 2017)

CV. Mitrajasa Perdana Anugrah adalah sebuah perusahaan yang bergerak dibidang jasa pengiriman barang dari perseroan komanditer yang menyediakan jasa pengiriman barang. Dalam pencatatan laporan pengiriman harian , CV. Mitrajasa Perdana Anugrah belum menggunakan komputer sebagai media untuk pencatatan transaksinya. Tetapi masih menggunakan buku dan email sebagai sarana untuk mencatat setiap transaksi yang terjadi. Transaksi yang dicatat atau diolah dalam laporan antara lain : data pengirim, data penerima, transaksi pengiriman barang, data kurir laporan data pengirim, laporan data penerima laporan transaksi pengiriman barang. laporan kurir. Semua laporan yang dibuat oleh admin setiap harinya kemudian dikirimkan lewat email. Dalam proses pembuatan laporan menggunakan Buku secara manual, banyak hal yang menjadi kendala dalam proses pengolahan laporan, antara lain data yang kurang efisiensi karena dalam pembuatan laporan perhari dilakukan dengan cara manual, sehingga seringkali terjadi kesalahan dalam menulis, buku yang digunakan bisa saja terkena air dan membuat data tersebut tidak bisa dibaca atau rusak,dan kerap kali buku catatan transaksi lupa meletakkannya bahkan buku tersebut hilang sehingga dapat menyebabkan kerugian bagi CV. Mitrajasa Perdana Anugrah. Owner tidak dapat mengetahui secara langsung data yang dibuat karena harus menunggu dikirimkan lewat surat elektronik atau email. Sebagai bahan pertimbangan dalam hal ini peneliti memilih untuk membangun sistem informasi jasa pengiriman barang berbasis web. Sistem informasi jasa pengiriman barang berbasis web dipilih dengan alasan agar owner dipusat yaitu purwokerto dapat mengakses langsung laporan yang dibuat oleh admin dari mana saja dan kapan saja, hal ini dikarenakan owner berada dikota yang berbeda dengan cabangnya.

Binary search dipilih karena metode ini lebih efisien dibandingkan metode sequential search. Hal ini dikarenakan metode Binary search dalam proses pencarian datanya dengan cara membagi data menjadi dua bagian dengan menentukan data indeks tengah, data indeks tengah merupakan data tengah yang diambil dari jumlah data $\mathrm{N}$ kemudian data yang dicari dibandingkan dengan indeks tengah, jika data ke-N yang dicari lebih besar dari indeks tengah maka data akan dibagi menjadi dua bagian kemudian dari setiap ujung data yang dipilih akan dibandingkan lagi 
dengan data yang dicari. Sedangkan pada metode sequential search dalam pencarian datanya dilakukan dengan membandingkan satu persatu semua data yang ada didalam array data, sehingga dalam proses pencarian tersebut jika data yang diproses dalam jumlah banyak, maka akan memerlukan waktu yang lama dan beban komputasi yang lebih besar

Metode binary search ini akan diaplikasikan untuk proses pencarian data pengirim, data penerima, data kurir, dan data transaksi pengiriman. Sehingga pada saat diperlukan, proses pencarian data tersebut dapat berlangsung lebih cepat sehingga waktu pembuatan laporan menjadi relatif lebih cepat dari sebelumnya.

\section{. TINJAUAN PUSTAKA}

\section{Sistem Informasi}

Manusia hidup di dunia penuh dengan sistem, di sekeliling manusia apa yang dilihat sebenarnya adalah kumpulan dari suatu sistem. Penerimaan mahasiswa baru, sistem perkuliahan, sistem perekonomian, sistem bisnis, sistem transportasi dan sebagainya merupakan contoh dari sistem. Sistem adalah sekelompok elemen- elemen yang terintegrasi dengan tujuan yang sama untuk mencapai tujuan.

Informasi adalah data yang diolah menjadi bentuk lebih berguna dan lebih berarti bagi yang menerimanya. Informasi juga disebut data yang diproses atau data yang memiliki arti. Informasi merupakan data yang telah diproses sedemikian rupa sehingga meningkatkan pengetahuan seseorang yang menggunakan. Para pembuat keputusan memahami bahwa informasi menjadi faktor kritis dalam menentukan kesuksesan atau kegagalan dalam suatu bidang usaha. Sistem apapun tanpa ada informasi tidak akan berguna, karena sistem tersebut akan mengalami kemacetan dan akhirnya berhenti.Informasi dapat berupa data mentah, data tersusun, kapasitas sebuah saluran informasi, dan sebagainya.

Sistem informasi merupakan sistem pembangkit informasi, kemudian dengan integrasi yang dimiliki antar sub sistem, maka sistem informasi akan mampu menyediakan informasi yang berkualitas, tepat, cepat dan akurat sesuai dengan manajemen yang membutuhkannya.

Pada lingkungan berbasis komputer, sistem informasi menggunakan perangkat keras dan perangkat lunak, jaringan telekomunikasi, manajemen basis data, dan berbagai bentuk teknologi informasi yang lain dengan tujuan untuk mengubah sumber data menjadi berbagai macam informasi yang dibutuhkan oleh pemakai.

Secara sederhana dapat dikatakan bahwa data diolah menjadi suatu informasi. Dan pada tahapan selanjutnya, sebuah informasi akan menjadi data untuk terciptanya informasi yang lain (Firman, Wowor, \& Najoan, 2016).

Terdapat lima jurnal yang digunakan peneliti sebagai tolak ukur mengapa sistem informasi laporan jasa pengiriman barang pada CV. Mitrajasa Perdana Anugrah harus dibangun : jurnal pertama dengan judul sistem informasi jasa pengiriman surat dan barang pada PT. Pos Indonesia sistem tersebut masih berbasis desktop (Supriati, Irmawan, \& Melandy, 2017), jurnal kedua dengan judul perancangan sistem informasi pengiriman barang berbasis web (studi kasus ekspedisi haji zarkasi Banjarmasin) sistem belum memiliki fungsi kelola kurir beserta laporannya (Noor \& Muhamad, 2017) , jurnal ketiga sistem informasi pemaketan barang pada alfath 
tours dan travel pacitan sistem belum memiliki fungsi kelola kurir dan laporannya serta keterangan berat barang yang akan dikirim (Lestari, 2014), jurnal keempat dengan judul perancangan sistem informasi pelaporan transaksi berbasis web pada PT. Pos Indonesia Batam sistem masih belum memiliki fungsi kelola kurir dan penerima serta laporannya (Tukino \& Amrizal, 2017), jurnal kelima dengan judul sistem informasi manajemen pada jasa expedisi pengiriman barang berbasis web sistem masih belum memiliki hak akses untuk owner, yang mana aktor ini dapat melihat laporan pengirim, penerima, pengiriman, dan kurir (Vikasari, 2018) . Oleh sebab itu dibangunlah sistem informasi laporan jasa pengiriman barang pada $\mathrm{CV}$. Mitrajasa Perdana Anugrah untuk menjawab segala permasalahan yang ada. WEB

World wide web atau sering di kenal sebagai web adalah suatu layanan sajian informasi yang menggunakan konsep hyperlink (tautan), yang memudahakan surfer (sebutan para pemakai komputer yang melakukan browsing atau penelusuran informasi melalui internet). Keistimewaan inilah yang telah menjadikan web sebagai service yang paling cepat pertubuhannya. Web mengijinkan pemberian highlight (penyorotan atau penggaris bawahan) pada kata-kata atau gambar dalam sebuah dokumen untuk menghubungkan atau menunjuk ke media lain seperti dokumen, frase, movie clip, atau file suara. Web dapat menghubungkan dari sembarang tempat dalam sebuah dokumen atau gambar ke sembarang tempat di dokumen lain. Dengan sebuah browser yang memiliki Grapihcal User Interface (GUI), linklink dapat dihubungkan ketujuannya dengan menunjuk link tersebut dengan mouse dan menekannya. (Palit, Rindengan, \& ST., 2015)

Metode PROTOTYPE

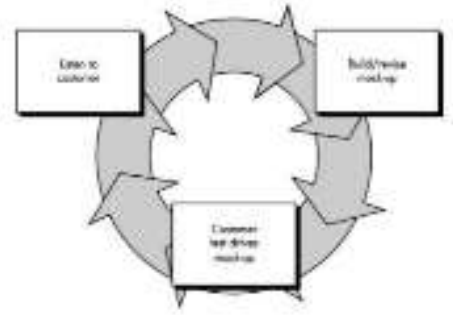

Gambar 1. Metode Prototype

(Purnomo, 2017)

(Purnomo, 2017), menyampaikan bahwa prototyping merupakan metode pengembangan perangat lunak, yang berupa model fisik kerja sistem dan berfungsi sebagai versi awal dari sistem. Dengan metode prototyping ini akan dihasilkan prototype sistem sebagai perantara pengembang dan pengguna agar dapat berinteraksi dalam proses kegiatan pengembangan sistem informasi. Agar proses pembuatan prototype ini, berhasil dengan baik adalah dengan mendefinisikan aturanaturan pada tahap awal, yaitu pengembang dan penguna harus satu pemahaman bahwa prototype dibangun untuk mendefinisikan kebutuhan awal. Prototype akan dihilangkan atau ditambahkan pada bagiannya sehingga sesuai dengan perencanaan dan analisis yang dilakukan oleh pengembang sampai dengan ujicoba dilakukan secara simultan seiiring dengan proses pengembangan. Ada 4 metodologi prototyping yang paling utama yaitu :

(1) Illustrative, menghasilkan contoh laporan dan tampilan layar.

(2) Simulated, mensimulasikan beberapa alur kerja sistem tetapi tidak menggunakan data real.

(3) Functional, mensimulasikan beberapa alaur sistem yang 
sebenarnya dan menggunakan data real.

(4) Evolutionary, menghasilkan model yang menjadi bagian dari operasional sistem.

\section{Paired Samples T-Test}

Paired Sample T-Test dengan SPSS

penelitian ini menggunakan jenis uji pairid sample T-test guna menguji apakah terdapat perbedaan antara sebelum dan sesudah perubahan UU No. 36 Tahun 2008. Dengan tingkat signifikansi yang ditetapkann adalah 5\% $(\alpha=0,05)$. Pengambilan keputusannya sebagai berikut : Jika probabilitas > 0,05, maka $\mathrm{Ha}$ atau Ho diterima.

Jika probabilitas < 0,05, maka $\mathrm{Ha}$ atau Ho ditolak (Hanifah \& Burhanudin, 2016)

METODE PENELITIAN Metode Pengembangan Sistem

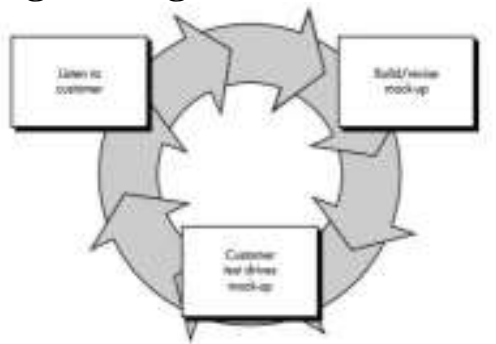

Gambar 2. Metode Prototype

(Purnomo, 2017)

\section{Analisis Sistem}

Tahap analisis adalah tahap untuk menganalisis masalah yang ada dengan melakukan observasi dan wawancara dengan user sistem, agar sistem dapat membantu agar proses adminitrasi laporan pengiriman barang di CV. Mitrajasa Perdana Anugrah lebih efisien.

\section{Desain Sistem}

Setelah melakukan tahap analisis, langkah berikutnya adalah tahap desain sistem yang akan dikembangkan dengan menerjemahkan data yang dianalisis dalam bentuk usecase diagram. Use Case Diagram merupakan pemodelan untuk kelakuan (behavior) sistem informasi yang dibuat. Use case mendiskripsikan sebuah interaksi antara satu atau lebih aktor yang terkait dengan sistem informasi yang akan dibuat. Berikut adalah usecase diagram mengenai Sistem Informasi Laporan Jasa Pengiriman Barang Pada CV. Mitrajasa Perdana Anugrah secara umum:

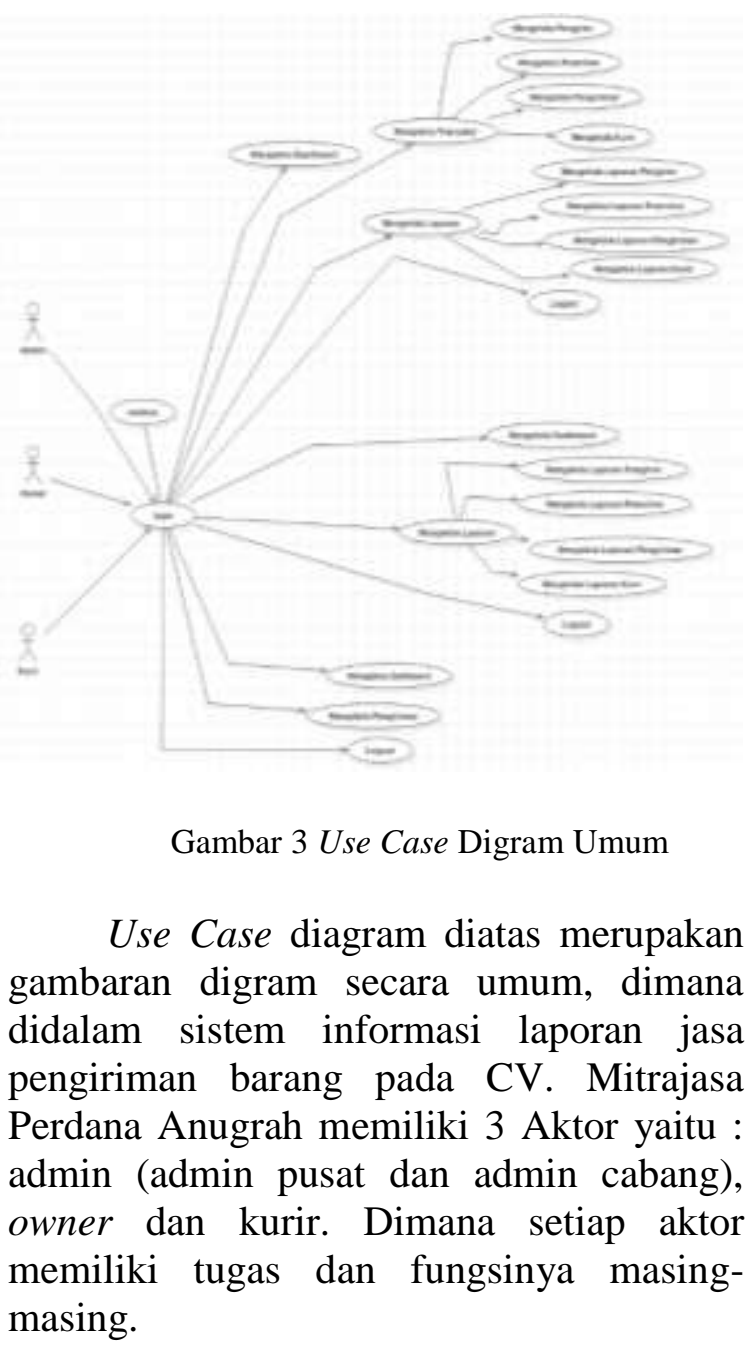




\section{Jơfeñ}

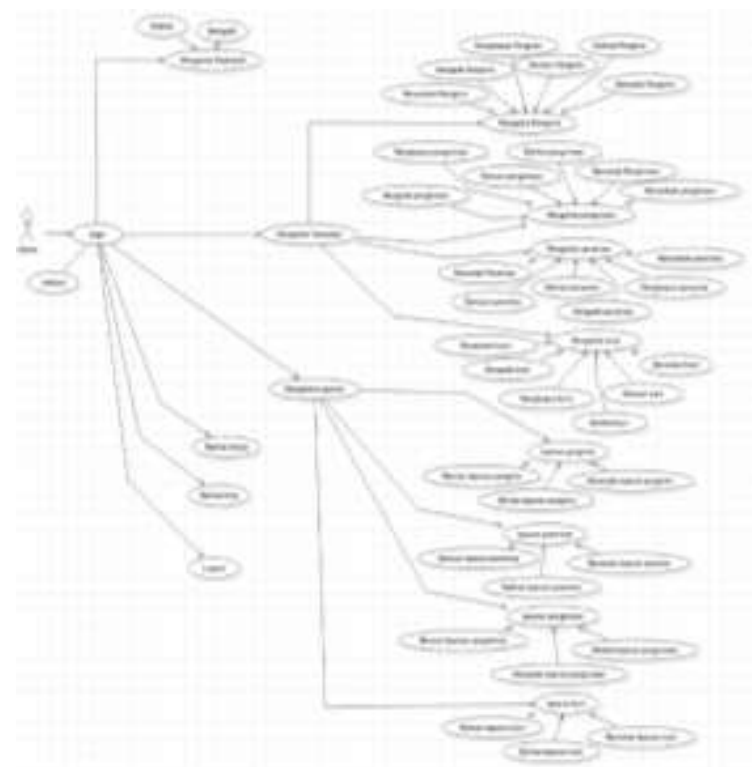

Gambar 4. Use Case Digram Admin

Use Case digram diatas merupakan gambaran dari apa saja yang dapat dilakukan oleh Admin. Berdasarkan fungsi yang ada Admin bertugas untuk melakukan adminitrasi (tambah data, edit data, hapus data, lihat data, cari data, cetak data) pada sistem seperti : mengelola data pengirim, mengelola data penerima, mengelola data pengiriman, mengelola data kurir, serta mencetak laporan-laporan yang ada.

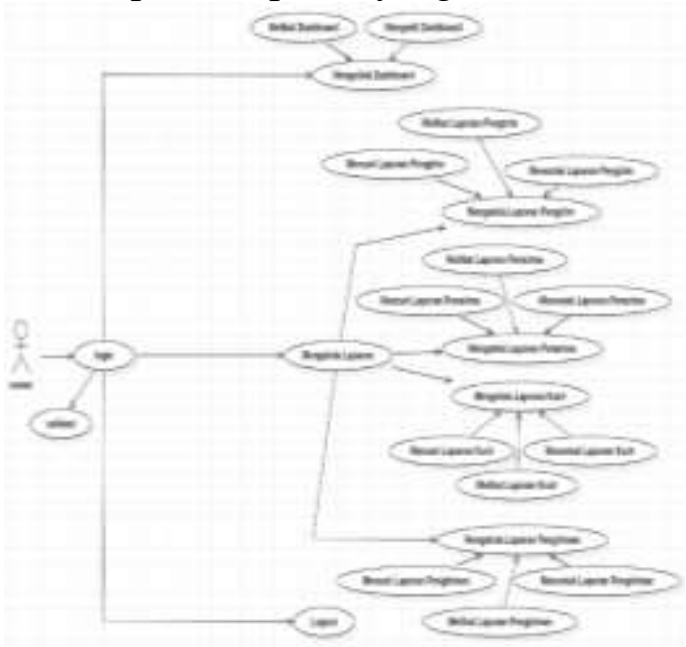

Gambar 5. Use Case Digram Owner

Use Case digram diatas merupakan use case gambaran dari apa saja yang dapat dilakukan oleh owner atau pemilik CV.
Mitrajasa Perdana Anugrah, dimana owner hanya dapat melihat laporan pengiriman.

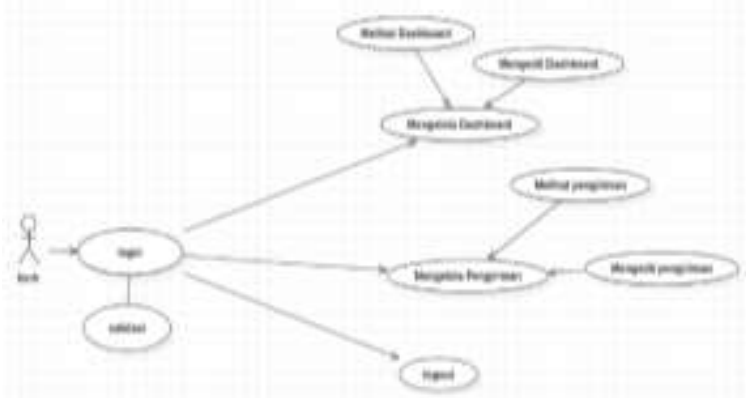

Gambar 6. Use Case Digram Kurir

Use case diagram diatas adalah gambaran dari apa saja yang dapat dilakukan oleh kurir. Dalam sistem ini kurir hanya dapat melihat laporan barang yang harus dikirim, dimana status barang adalah belum proses. Setelah itu kurir dapat mengklaim barang yang akan dihantar ketempat tujuan, setelah barang tersebut selesai dihantar, kurir dapat mengkonfirmasi pengiriman barang yang telah dihantar.

\section{Membuat Prototype}

Peneliti menanyakan kepada pemilik CV. Mitrajasa Perdana Anugrah tentang prototype yang sudah dibuat, apakah sesuai atau tidak dengan kebutuhan sistem.

\section{Menguji Prototype}

Setelah prototype sistem yang dibuat sudah sesuai dengan kebutuhan pengguna, selanjutnya peneliti akan melakukan pengujian sistem agar sistem yang dibuat dapat berjalan sesuai dengan harapan pengguna sistem. Pengujian yang dilakukan adalah dengan pengujian white box testing dan black box testing.

Pengujian white box testing dilakukan untuk menguji apakah pengkodean sistem dapat berjalan sesuai dengan harapan atau belum baik itu terkait logical path maupun test case yang mngerjakan kumpulan kondisi dan pengulangan yang spesifik. 
Sedangkan pengujian black box dilakukan untuk menguji apakah tampilan antarmuka (user interface) sudah sesuai dengan yang diharapkan oleh pengguna.

\section{Memperbaiki Prototype}

Sistem disesuaikan dengan keinginan pemilik CV. Mitrajasa Perdana Anugrah dan kebutuhan sistem. Jika sudah sesuai sistem siap digunakan

\section{Mengembangkan Versi Produksi}

Sistem mulai dikembangkan dengan prototype yang sudah dibuat.

\section{HASIL DAN PEMBAHASAN}

\section{Implementasi Antarmuka}
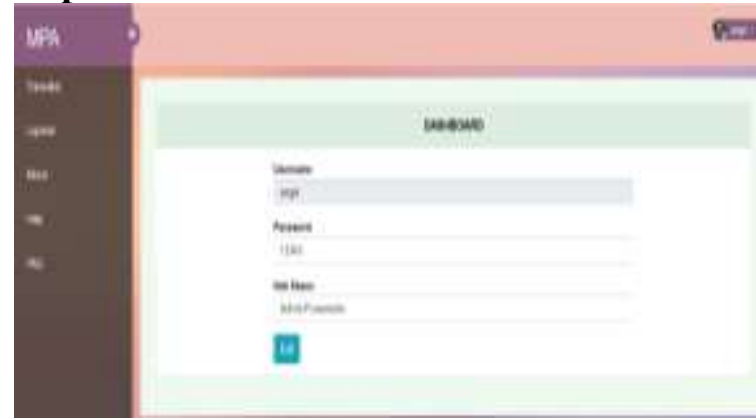

Gambar diatas adalah halaman beranda Admin. Halaman ini memiliki akses ke dalam sistem informasi laporan jasa pengiriman barang pada CV. Mitrajasa Perdana Anugrah yaitu meliputi pengelolaan data transaksi, pengelolaan data laporan, about,help dan faq.
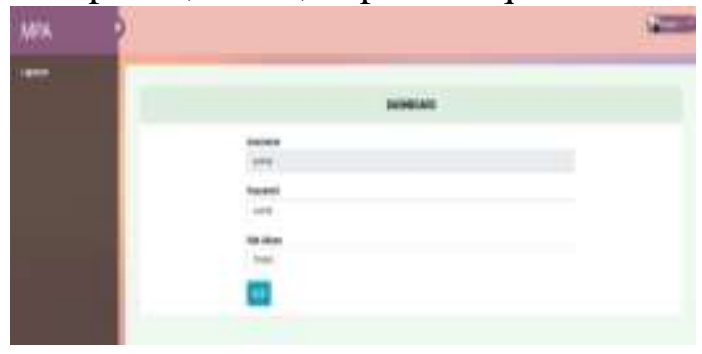

Gambar diatas adalah halaman beranda Owner. Halaman ini memiliki akses ke dalam sistem informasi laporan jasa pengiriman barang pada CV. Mitrajasa Perdana Anugrah yaitu meliputi melihat dan mencetak laporan-laporan yang ada pada sistem Mpa Express seperti laporan pengirim, laporan penerima, laporan pengiriman dan laporan kurir.

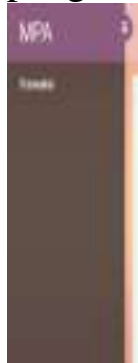

Gambar diatas adalah halaman beranda Kurir. Halaman ini memiliki akses ke dalam sistem informasi laporan jasa pengiriman barang pada CV. Mitrajasa Perdana Anugrah yaitu meliputi mengklain dan menyelesaikan barang yang akan dikirim.

\section{Hasil Uji Manfaat}

Tabel 1. Hasil Uji Manfaat

\begin{tabular}{|c|c|c|c|c|c|c|}
\hline \multirow{5}{*}{ Efektivitas } & \multirow[b]{2}{*}{ Kriteria } & \multicolumn{4}{|c|}{ Pertanyaan } & \multirow[b]{2}{*}{$\begin{array}{l}\text { Rata- } \\
\text { rata }\end{array}$} \\
\hline & & 1 & 2 & 3 & 4 & \\
\hline & $\mathrm{S}$ & 56.7 & 63.3 & 70.0 & 80.0 & \multirow{3}{*}{95.0} \\
\hline & SS & 40.0 & 33.3 & 20.0 & 16.7 & \\
\hline & Total & 96.7 & 96.6 & 90.0 & 96.7 & \\
\hline \multirow{5}{*}{ Efisiensi } & \multirow[b]{2}{*}{ Kriteria } & \multicolumn{3}{|c|}{ Pertanyaan } & & \multirow[b]{2}{*}{ Rata- } \\
\hline & & 1 & 2 & 3 & 4 & \\
\hline & $\mathrm{S}$ & 50.0 & 50.0 & 63.3 & 70.0 & \multirow{3}{*}{97.5} \\
\hline & SS & 46.7 & 46.7 & 36.7 & 26.7 & \\
\hline & Total & 96.7 & 96.7 & 100.0 & 96.7 & \\
\hline \multirow{5}{*}{$\begin{array}{l}\text { Economic } \\
\text { Risk } \\
\text { mitigation }\end{array}$} & \multirow[b]{2}{*}{ Kriteria } & \multicolumn{3}{|c|}{ Pertanyaan } & & \multirow[b]{2}{*}{$\begin{array}{l}\text { Rata- } \\
\text { rata }\end{array}$} \\
\hline & & 1 & 2 & 3 & 4 & \\
\hline & $\mathrm{S}$ & 73.3 & 70.0 & 66.7 & 53.3 & \multirow{3}{*}{94.9} \\
\hline & SS & 23.3 & 30.0 & 33.3 & 30.0 & \\
\hline & Total & 96.6 & 100.0 & 100.0 & 83.3 & \\
\hline
\end{tabular}

Berdasarkan hasil yang ditampilkan pada tabel frekuensi dan pie chart, diperoleh persentase untuk efektivitas sebesar 95\%, efisiensi sebesar 97,5\%, dan economic risk mitigation sebesar 94,9\%. Berdasarkan hasil dari besar persentase tersebut, maka dapat disimpulkan bahwa Sistem Informasi Laporan Jasa Pengiriman pada CV. Mitrajasa Perdana Anugrah sangat berguna 
berguna untuk meningkatkan efisiensi waktu pembuatan laporan pengiriman.

\section{PENUTUP}

Berdasarkan hasil dari penelitian Sistem Informasi Laporan Jasa Pengiriman Barang Pada CV. Mitrajasa Perdana Anugrah, maka penulis dapat menyimpulkan :

1. Sistem Informasi Laporan Jasa Pengiriman Barang Pada CV. Mitrajasa Perdana Anugrah Berbasis Web berguna untuk meningkatkan efisiensi waktu pembuatan laporan pengiriman sesuai dengan tujuan dan manfaat dalam penelitian inI. Dapat disimpulkan berdasarkan hasil uji manfaat menunjukkan perbedaan prosentase dari masing-masing karakteristik kualitas yang diambil dari 30 responden. Prosentase untuk effectiveness adalah sebesar 95\%, Efficiency sebesar 97,5\%, economic risk mitigation sebesar 94,9\%. Berdasarkan hasil tersebut, nilai prosentase Efficiency adalah yang paling tinggi diantara prosentase karakteristik kualitas lainnya (effectiveness, economic risk mitigation).

2. Dengan Sistem Informasi Laporan Jasa Pengiriman Barang Pada CV. Mitrajasa Perdana Anugrah dapat membantu proses adminitrasi laporan menjadi lebieh efisien.

\section{DAFTAR PUSTAKA}

Anggraeni, A., Sukmaaji, A., \& Sutanto, T. (2016). Rancang Bangun Aplikasi Kamus Indonesia - Korea Menggunakan Metode Algoritma Binary Search Berbasis Android. JSIKA Vol. 5, No. 3. Tahun 2016 ISSN 2338-137X, 10.

Bevan, N., Earthy, J., Carter, J., \& Geis, T. (2017). New ISO Standards for Usability, Usability Reports and Usability Measures. M. Kurosu (Ed.): HCI 2016, Part I, LNCS 9731, pp. 268-278, 2016. , 12.
Enterprise, J. (2016). Pemrograman Bootstrap untuk Pemula. Jakarta: PT Elex Media Komputindo.

Hanifah, \& Burhanudin. (2016). Analisis Manajemen Laba Menggunakan DiscrEetionary Accrual Untuk Merespon Perubahan Tarif Pajak Sebelum Dan Sesudah Berlakunya UU NO. 36 Tahun 2008 PT. HM Sampoerna Tbk. Periode 20052014. Jurnal Akuntansi. Vol. 3. No.1 Januari 2016 ISSN 2339-2436, 22.

Harison, \& Syarif, A. (2016). Sistem Informasi Geografis Sarana Pada Kabupaten Pasaman Barat. Vol. 4 No. 2 Oktober 2016 Jurnal TEKNOIF ISSN: 2338-2724, 4, 11.

Mqbalusta, M. S., Firdaus, R. F., \& Rahmadi, H. (2015). Pengujian Aplikasi Menggunakan Black Black Box Testing Boundary Value Analysis (Studi Kasus : Aplikasi Prediksi Kelulusan SNMPTN). Jurnal Ilmiah Teknologi Terapan, 6.

Palit, R. V., Rindengan, S. M., \& ST., M. A. (2015). Rancangan Sistem Informasi Keuangan Gereja Berbasis Web Di Jemaat GMIM Bukit Moria Malalayang. E-Journal Teknik Elektro dan Komputer vol. 4 no. 7 (2015), ISSN : 2301-8402, 7.

Purnomo, D. (2017). Model Prototyping Pada Pengembangan Sistem Informasi. JIMP - Jurnal Informatika Merdeka Pasuruan Vol.2 No.2 Agustus 2017 ISSN 2503-1945, 8. 